Gut, 1982, 23, 637-642

\title{
Diurnal changes in serum unconjugated bile acids in normal man
}

\author{
K D R SETChELL, A M LAWSON, E J BLACKSTOCK, and G M MURPHY \\ From the Division of Clinical Chemistry, Clinical Research Centre, Harrow, Middlesex, and the \\ Gastroenterology Unit, Department of Medicine, Guy's Hospital Medical School, London
}

SUMMARY Unconjugated bile acids were measured using gas chromatography-mass spectrometry in the serum of two subjects throughout a 24 hour period and in two other subjects over a six hour period after breakfast. Unconjugated bile acids were found in all samples of serum and included cholic, chenodeoxycholic, deoxycholic, $3 \beta, 7 \alpha$-dihydroxy- $5 \beta$-cholanic (isochenodeoxycholic), ursodeoxycholic, $3 \beta, 7 \beta$-dihydroxy-5 $\beta$-cholanic (iso-ursodeoxycholic), $3 \beta$ hydroxy-5-cholenoic, and lithocholic acids. The maximum concentration of each bile acid generally occurred between breakfast and dinner and total unconjugated bile acid concentrations attained levels of between 2-3 $\mu \mathrm{mol} / 1$. Concentrations increased after breakfast and were often as high as $30-40 \%$ of the conjugated bile acid glycocholate, but returned to fasting levels in the absence of lunch. The intestinal absorption of unconjugated bile acids is therefore of greater quantitative importance than was previously thought.

The first step in the formation of secondary bile acids is usually deconjugation, and, in normal man, about one-third of the bile acid pool daily undergoes deconjugation by intestinal bacteria. ${ }^{2} 3$ Consequently, the majority of bile acids found in the lower ileum and colon are normally unconjugated. ${ }^{4}$ Many important functions have been ascribed to unconjugated bile acids. It has been suggested that they are important as bacteriostatic agents in the distal ileum, ${ }^{5}$ in the maintenance of normal bile acid pool size,${ }^{2}$ as physiological laxatives, ${ }^{6}$ and in the control of bile acid synthesis. ${ }^{7}$

Bacterial degradation of bile acids also includes dehydration, dehydrogenation, and epimerisation and, although a large number of bile acid bacterial metabolites may be normally excreted, ${ }^{8}$ little is known of their absorption.

This report describes for the first time the diurnal variation of serum unconjugated bile acid concentrations in normal man.

\section{Methods}

SUBJECTS

Serum unconjugated bile acids were measured in

Received for publication 23 October 1981 four adult males (hospital staff) aged 28-45 years. Liver function tests were normal and none of the subjects had any evidence of gastrointestinal disease. Samples of whole blood were obtained via an indwelling intravenous cannula and the sera stored at $-20^{\circ} \mathrm{C}$. In two subjects samples were obtained throughout a 24 hour period in which three solid meals were taken at $19.30 \mathrm{~h}, 08.00 \mathrm{~h}$, and $13.00 \mathrm{~h}$ and a snack (consisting of biscuits and milk) at $23.00 \mathrm{~h}$. In the other two subjects, after a single solid meal (breakfast) taken at $10.30 \mathrm{~h}$, blood samples were collected for a five hour period during which no more food was eaten. Bile acids were extracted from serum using Amberlite XAD- $7^{9}$ and the unconjugated bile acids were isolated by anion exchange chromatography on a lipophilic Sephadex gel diethylaminohydroxypropyl Sephadex LH-20. ${ }^{10}$ Bile acids were quantified as their methyl estertrimethylsilyl ether derivatives using gas chromatography-mass spectrometry. Gas chromatographymass spectrometry was performed using a Varian Aerograph gas chromatograph equipped with a $3 \%$ Hi-Eff 8-BP column $(2 \mathrm{~m} \times 4 \mathrm{~mm})$ heated at $235^{\circ} \mathrm{C}$ and coupled to a Varian MAT-731 double focusing mass spectrometer operated in the selected ion monitoring mode at low resolution. Accelerating voltage switching was used to focus the ions of mass/charge $(\mathrm{m} / \mathrm{z}) 368,370$, and 372 chosen because 
they are characteristic ions in the mass spectra of Me-TMS ether derivatives of mono-, di, and trihydroxylated bile acids (Fig. 1). Bile acids were quantified by measuring the ratio of their peak height response to that of the internal standard (coprostanol) and comparing with a series of calibration standards of authentic bile acids. Authentic bile acids were obtained by either Steraloids or the Medical Research Council Steroid Reference collection (curator Professor D N Kirk, Westfield College, Hampstead, London, UK) and their purity checked by thin layer chromatography
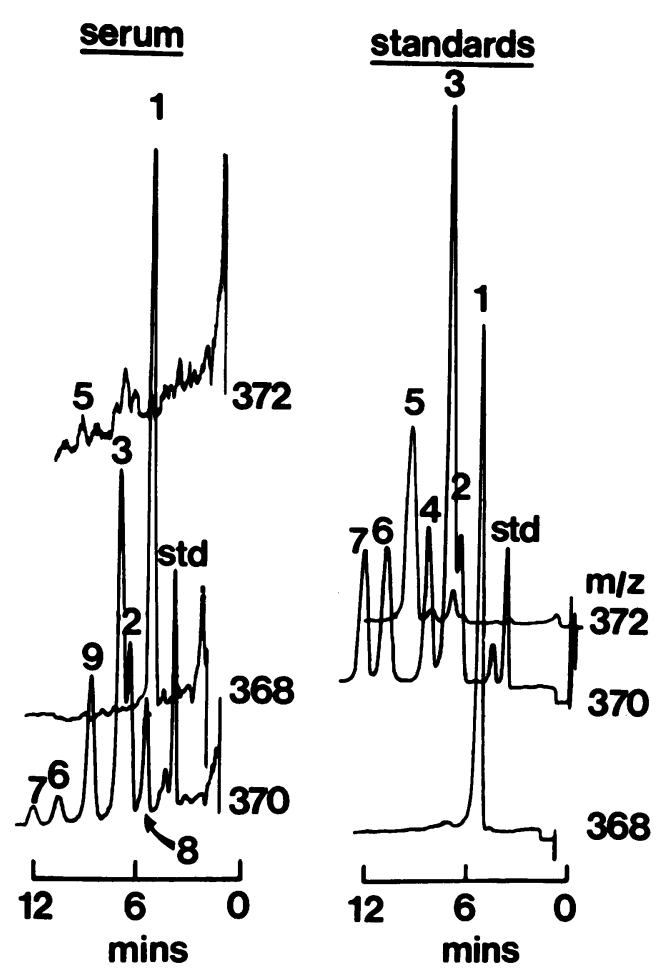

Fig. 1 Qualitative gas chromatography-mass spectrometric analysis of the methyl ester-trimethylsilyl ether derivatives of a mixture of authentic bile acids (50 pmol) and the unconjugated bile acid fraction from the serum $(1 \mathrm{ml})$ of a normal adult. Selected ion monitoring chromatograms of the ions $\mathrm{m} / \mathrm{z} 368,370$, and 372 are shown and the following bile acids are indicated: (1) cholic acid, (2) deoxycholic acid, (3) chenodeoxycholic acid, (4) hyodeoxycholic acid,

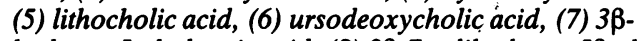
hydroxy-5-cholenoic acid, (8) $3 \beta, 7 \alpha$-dihydroxy-5 $\beta$-cholanic acid, (9) $3 \beta, 7 \beta$-dihydroxy-5 $\beta$-cholanic acid. Coprostanol (10 pmol) was the internal standard used and gas chromatography was performed on a $1 \% \mathrm{Hi}$-eff $8 B \mathrm{PP}$ packed column at $235^{\circ} \mathrm{C}$ isothermal. and gas chromatography and found to be $>95 \%$ pure.

The high sensitivity of the technique allowed a limit of detection of approximately $10 \mathrm{pmol}$ bile acid, this being equivalent to a serum concentration of $0.005 \mu \mathrm{mol} / 1$. The within batch precision of replicate analyses gave coefficients of variation of between $5-13 \%$ for the different bile acids.

Cholic, chenodeoxycholic, deoxycholic, lithocholic, ursodeoxycholic, and $3 \beta$-hydroxy-5-cholenoic acids were identified from their complete mass spectra and gas chromatographic characteristics. $3 \beta, 7 \alpha$-Dihydroxy-5 $\beta$-cholanic and $3 \beta, 7 \beta$-dihydroxy$5 \beta$-cholanic acids were tentatively identified from their complete mass spectra, gas chromatographic retention data, and mass ion responses, as it was not possible to obtain authentic standards to allow their definitive identification.

Serum glycocholate concentrations were determined by radioimmunoassay (Abbott Laboratories Ltd, Basingstoke, UK).

\section{Results}

Unconjugated bile acids were found in all serum samples analysed (Fig. 1). Although there were quantitative and qualitative differences between the 24 hour profiles of the individual bile acids, the two sets of data had many features in common (Fig. 2). During the 24 hour period the maximum concentration of most of the bile acids occurred between breakfast and dinner, little change being found during the period after midnight and before breakfast.

In both subjects deoxycholic acid was the unconjugated bile acid present in the highest concentration. The time at which the maximum concentration of deoxycholic acid occurred in each subject generally coincided with the peak concentration of ursodeoxycholic, iso-ursodeoxycholic, and iso-chenodeoxycholic acids but not of cholic and chenodeoxycholic acids. In neither subject did unconjugated lithocholic acid concentrations ever exceed $0.05 \mu \mathrm{mol} / 1(18 \mathrm{ng} / \mathrm{ml})$ and in many samples this bile acid was undetectable. In each subject the changes in chenodeoxycholic acid concentration tended to accompany those of the cholic acid concentration. In all of the samples analysed the percentage of cholic acid was greater than that of chenodeoxycholic acid (Fig. 2).

In the two other subjects, after breakfast $(10.30 \mathrm{~h})$, levels of glycine conjugated cholic acid increased and were still raised $4 \frac{1}{2}$ hours later (Fig. 3 ). In contrast, concentrations of unconjugated bile acids, which often reached about $50 \%$ of the corresponding glycocholate concentration, returned 

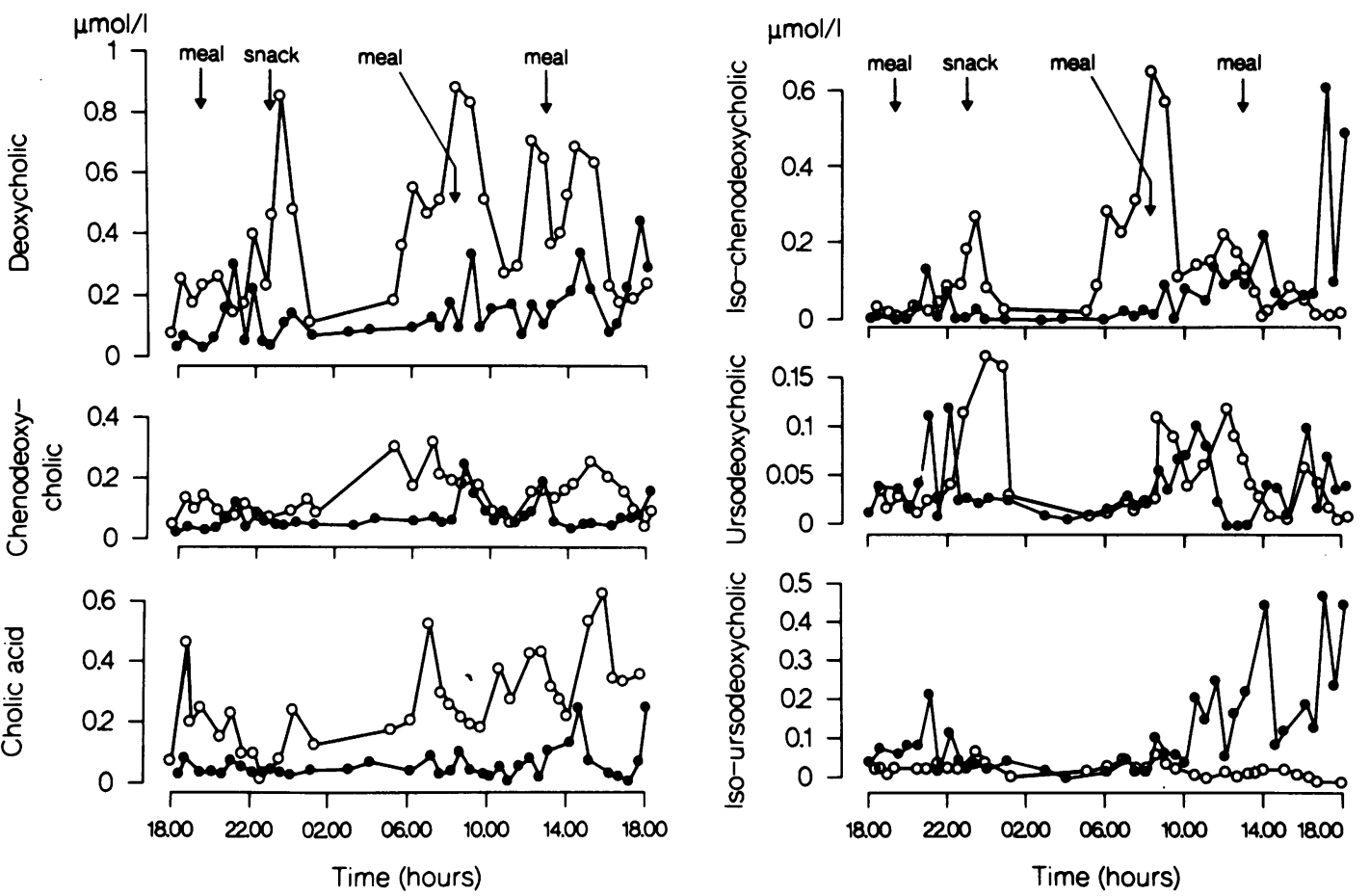

Fig. 2 Changes in serum unconjugated bile acid concentrations ( $\mu$ molll) throughout a 24 hour period in two normal adults (०๑).

to pre-breakfast values within three hours (Fig. 3). Iso-chenodeoxycholic acid was the predominant bile acid of the unusual unconjugated bile acids detected (Fig. 3).

\section{Discussion}

A large number of unconjugated bile acids are to be found in the fasting sera of normal subjects and their concentration increases after meals.

Serum bile acids represent that fraction of the biliary bile acids which, after absorption from the intestinal lumen into the portal vein, escape extraction by the liver. Unconjugated bile acids are produced by bacterial action on the conjugated biliary acids and, although some bacterial alteration of conjugated bile acids may occur without deconjugation, ${ }^{3}$ the majority of newly formed secondary bile acids are unconjugated. It is generally accepted that all the bile acids excreted by the normal liver are conjugated and this view is supported by the observation that unconjugated bile acids are not normally found in the duodenum and upper jejunum. ${ }^{11}$ Serum unconjugated bile acid concentrations may therefore be regarded as indices of the absorption of newly formed secondary bile acids.

Many previous studies have suggested that, compared with the amount of conjugated bile acids, the unconjugated bile acid fraction in the sera of normal subjects is negligible. The analytical technique applied to the analysis of unconjugated bile acids in serum utilises the lipophilic anion exchange gel, diethylaminohydroxypropyl Sephadex LH-20, which affords a specific separation of unconjugated bile acids from conjugates which are retained on this gel. ${ }^{10}$ The main advantages of using this gel are the high degree of purification which is attained, the inert nature of the gel which avoids degradation of bile acids, and the ability to separate neutral steroids, of which cholesterol is quantitatively the most important, from unconjugated bile acids which would otherwise interfere in the subsequent gas chromatography-mass spectrometry analysis. The absolute specificity of 

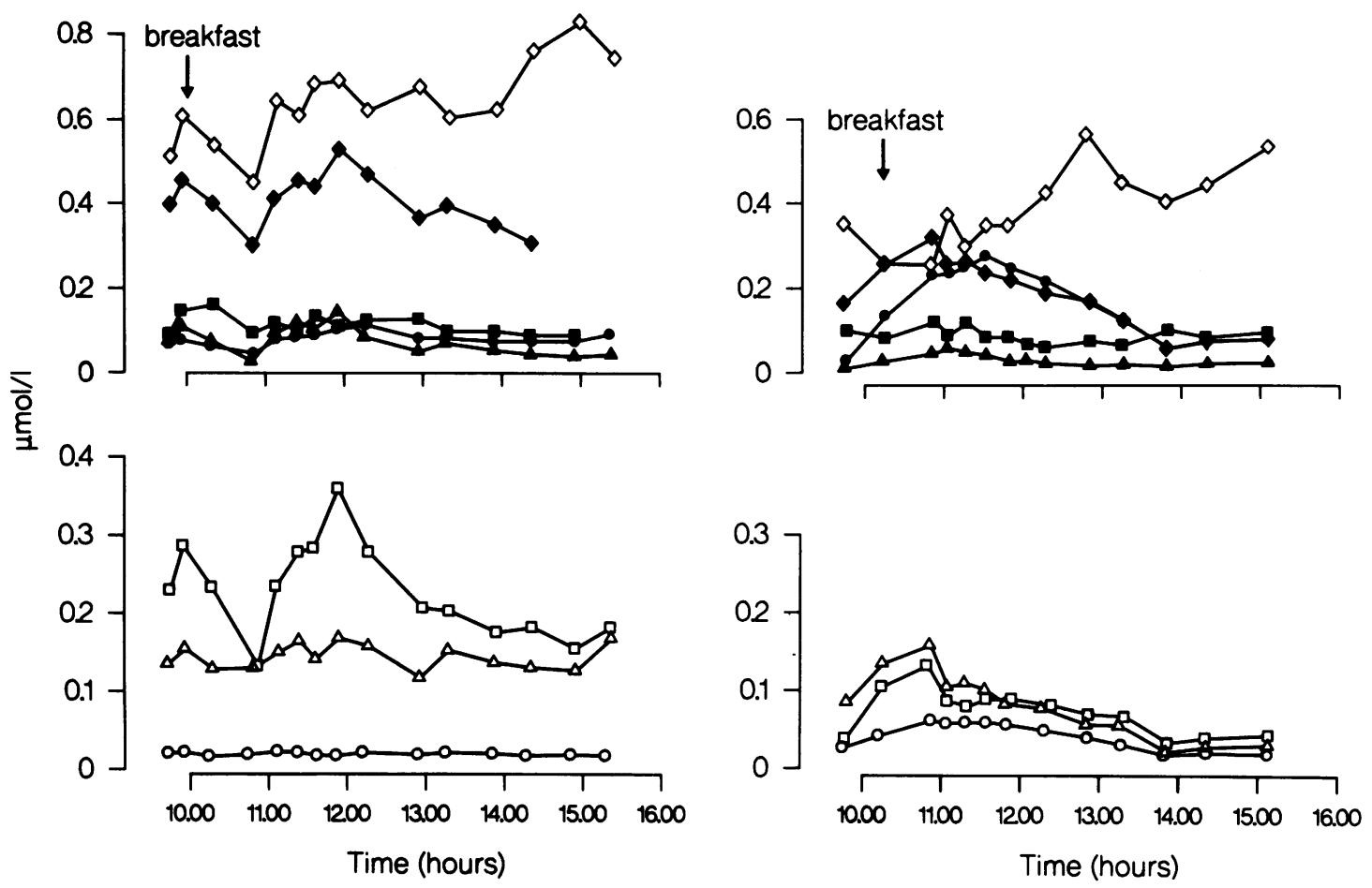

Fig. 3 Changes in the serum concentration ( $\mu$ molll) of glycine conjugated cholic acid $(\diamond)$ and a number of unconjugated bile acids in two subjects over a six hour period during which a single solid meal (breakfast, $10.30 \mathrm{~h}$ ) was given. Unconjugated deoxycholic $(\bullet)$, chenodeoxycholic $(\boldsymbol{\Delta})$, cholic $(\boldsymbol{\square})$, the total of all other unconjugated bile acids detected $(\diamond)$, iso-chenodeoxycholic $(\square)$, iso-ursodeoxycholic $(\Delta)$, and lithocholic $(0)$ are represented.

mass spectrometry and its high sensitivity when operated in a selected ion monitoring mode provides the basis for the quantitative determination of unconjugated bile acids isolated by the gel. Our results show that in fasting sera the concentration of unconjugated bile acids may be $30-40 \%$ that of the conjugated bile acid glycocholate, corroborating the observation of Makino et al. ${ }^{12}$ These results are supported by recent studies, in which unconjugated bile acids have been isolated from serum by thin layer chromatography, ${ }^{13}$ high pressure liquid chromatography, ${ }^{4}$ and lipophilic anion exchange chromatography ${ }^{1516}$ before their measurement by radioimmunoassay, ${ }^{13}$ enzyme immunoassay, ${ }^{14}$ 15 and gas chromatography-mass spectrometry. ${ }^{16}{ }^{\prime}$

Bile acids may be absorbed from the intestinal lumen by either passive or active transport mechanisms. ${ }^{17}$ While the above results do not allow any definitive statement to be made on the mode or site of transport, and unconjugated bile acids could conceivably be absorbed in the ileum by an active transport process, it would be expected that unconjugated bile acids would be absorbed by passive non-ionic diffusion from the colonic lumen. ${ }^{18}$ The appearance of peak concentrations in serum unconjugated bile acids within 30-60 minutes of breakfast, indicates that they are not the result of intestinal bacterial action on the conjugated bile acids recently discharged from the gall bladder. These early increases in serum unconjugated bile acid concentrations would suggest that they are derived from a pool of unconjugated bile acids sequestered in the semi-liquid contents of the lower intestine. Food ingestion increases colonic motility ${ }^{19}$ and, hence, the contact of the colonic content with the colonic mucosa, resulting in increased absorption. Studies of faecal bile acid excretion in normal subjects have demonstrated that there is a complex mixture of unconjugated bile acids present in the human colon. ${ }^{20}$ This complexity is the result of the numerous possible bacterial transformations which may accompany deconjugation. ${ }^{21}$ The present study indicates that many of these bile acid metabolites may be absorbed and spill over into the 
peripheral circulation. What determines the preferential absorption of some metabolites over others is unknown. Clearly such factors as aqueous solubility, adsorption to insoluble food residues, binding to bacteria, and luminal $\mathrm{pH}$ may all be involved. ${ }^{18}$

Serum bile acid measurements have long been regarded by many as providing sensitive and specific indices of liver function. ${ }^{22-24}$ With a few exceptions ${ }^{12-16}$ previous studies have not distinguished between serum conjugated and unconjugated bile acids. Thus the origin of the unusual bile acids often found in the sera from patients with liver disease $^{1625}$ remains uncertain. Whether unconjugated bile acids such as iso-chenodeoxycholic acid, iso-ursodeoxycholic acid, and $3 \beta$-hydroxy-5cholenoic acid are synthesised in the liver or the intestine is unknown. Although the finding of these bile acids in the unconjugated fraction from normal sera does not prove them to be of intestinal origin, it does suggest that their presence is physiological rather than pathological and that their formation is not necessarily indicative of liver disease. In this context it must be noted that all subjects in the present study were male and that in this preliminary study no attempt was made to assess the role of factors such as small or large intestinal transit time and type of meal on the proportion of bile acids present in serum as unconjugated bile acids.

Increased concentrations of fasting serum unconjugated bile acids have been found in patients with small bowel bacterial overgrowth and ileal resection. ${ }^{26}$ The explanation for this finding was the increased bacterial degradation of the conjugated bile acids coupled with the less efficient hepatic clearance of unconjugated bile acids from the peripheral circulation. ${ }^{26} 27$ The diurnal variation in serum unconjugated bile acid concentrations in patients with small bowel bacterial overgrowth has not been studied but the results of the present study suggest that their concentrations after meals would be even higher than normal subjects in the fasting state.

Ileal resections may often be accompanied by bile acid malabsorption, diarrhoea, and steatorrhoea. In some patients, however, colonic absorption of bile acids appears to be sufficient to prevent bile acid associated diarrhoea. ${ }^{28}$ The above observations suggest that the determination of postprandial serum unconjugated bile acid concentrations will provide a direct means of monitoring colonic absorption and thus of estimating the role of bile acids in associated diarrhoea and/or steatorrhoea.

In the past, much attention has been paid to malabsorbed or faecal bile acids, while the absorption of unconjugated bile acids, particularly in intestinal disease, including inflammatory bowel disease and colonic cancer, has received little consideration. The accurate measurement of serum unconjugated bile acids, however, provides a direct way of following the formation and absorption of secondary bile acids.

The authors wish to thank $\mathrm{Mr} \mathrm{M}$ Madigan for technical assistance in mass spectrometry and are grateful to Dr C C Booth and Professor $\mathrm{R} \mathrm{H}$ Dowling for their helpful advice during this work. GMM is supported by the Wellcome Trust.

\section{References}

1 Setchell KDR, Lawson AM, Blackstock EJ, Murphy GM. Meal induced absorption of newly formed secondary bile acids. Clin Sci 1981; 60: 23P.

2 Garbutt JT, Wilkins RM, Lack L, Tyor MP. Bacterial modification of taurocholate during enterohepatic recirculation in normal man and patients with small intestinal disease. Gastroenterology 1970; 59: 553-66.

3 Hepner GW, Hofmann AG, Thomas PJ. Metabolism of steroid and amino acid moieties of conjugated bile acids in man. J Clin Invest 1972; 51: 1889-1905.

4 Northfield TC, Draser BS, Wright JT. Value of small intestinal bile acid analysis in the diagnosis of the stagnant loop syndrome. Gut 1973; 14: 341-7.

5 Floch MH, Gersengoren W, Elliot S, Spiro HM. Bile acid exhibition of the intestinal micro-flora - a function for simple bile acids. Gastroenterology 1971; 61: 228-33.

6 Heaton K. Bile salts and the function of the colon. In: Bile salts in health and disease. Edinburgh and London: Churchill Livingstone, 1972: 111-2.

7 Low-Beer TS, Nutter Sheila. Colonic bacterial activity, biliary cholesterol saturation and the pathogenesis of gallstones. Lancet 1978; 2: 1063-4.

8 Eneroth P, Gordon B, Sjövall J. Characterisation of trisubstituted cholanic acids in human faeces. $J$ Lipid Res 1966; 7: 524-31.

9 Barnes S, Chitranukroh A. A simplified procedure for the isolation of bile acids from serum based on a batch extraction with the non-ionic resin-Amberlite XAD-7. Ann Clin Biochem 1977; 14: 237-9.

10 Almé B, Bremmelgaard A, Sjövall J, Thomassen P. Analysis of metabolic profiles of bile acids in urine using a lipophilic anionic exchanger and computerized gas-liquid chromatography-mass spectrometry. $J$ Lipid Res 1977; 18: 339-62.

11 Northfield TC, McColl I. Postprandial concentrations of free and conjugated bile acids down the length of the normal human small intestine. Gut 1973; 14: 513-8.

12 Makino I, Nakagawa S, Mashimo K. Conjugated and unconjugated serum bile acid levels in patients with hepatobiliary diseases. Gastroenterology 1969; 56: 1033-9. 
13 Matern S, Tietjen KE, Fackler O, Hinger R, Herz R, Gerok W. Bioavailability or ursodeoxycholic acid in man: studies with a radioimmunoassay for ursodeoxycholic acid. In: Paumgartner G, Stiehl A, Gerok W, eds. Biological effects of bile acids. Lancaster: MTP Press, 1979: 109-18.

14 Okuyama S, Kokubun N, Hieashidate S, Uemura D, Hirata Y. A new analytical method of individual bile acids using high performance liquid chromatography and immobilised $3 \alpha$-hydroxysteroid dehydrogenase in column form. Chem Lett (Japan) 1979; 12: 1443-6.

15 Kimura H, Suzuki N, Sato T, Goto J, Nambara T. Separatory determinations of free and conjugated bile acids in human serum. Jpn J Clin Chem 1979; 8: 126-30.

16 Bremmelgaard A, Almé B. Analysis of plasma bile acid: profiles in patients with liver disease associated with cholestasis. Scand J Gastroenterol 1980; 15: 593-600.

17 Dietschy JM. Mechanisms for the intestinal absorption of bile acids. J Lipid Res 1968; 9: 297-309.

18 Mekhjian HS, Phillips SF, Hofmann AF. Colonic absorption of unconjugated bile acids. Perfusion studies in man. Dig Dis Sci 1979; 24: 545-50.

19 Smith FW, Sleisenger MH. Physiology of the colon. In: Sleisenger MH and Fordtran J, eds. Gastrointestinal disease. Philadelphia: Saunders, 1978: 2: 1523-48.

20 Bergstrom $S$, Danielsson $H$. Formation and metabolism of bile acids. In: Code CF, ed. Handbook of physiology: bile, digestion, ruminal physiology.
Washington: American Physiological Society, 1968: 5: 2391-404.

21 Midtvedt T, Norman A. Bile acid transformation by microbial strains belonging to genera found in intestinal contents. Acta Pathol Microbiol Scand 1967; 71: 629-38.

22 Kaplowitz N, Kok E, Javitt NB. Postprandial serum bile acids for the detection of hepatobiliary disease. JAMA 1973; 225: 292-3.

23 Korman MG, Hofmann AF, Summerskill WH. Assessment of activity in chronic active liver disease: Serum bile acids compared with conventional tests and histology. N Engl J Med 1974; 290: 1399-402.

24 Barnes S, Galla GA, Trash DB, Morris JJ. Diagnostic value of serum bile acid estimations in liver disease. $J$ Clin Pathol 1975; 28: 506-9.

25 Summerfield JA, Billing BH, Shackleton CHL. Identification of bile acids in the serum and urine in cholestasis. Evidence for $6 \alpha$-hydroxylation of bile acids in man. Biochem J 1976; 154: 507-16.

26 Lewis B, Panveliwalla D, Tabaqchali S, Wootton DP. Serum bile acids in the stagnant loop syndrome. Lancet 1969; 1: 219-20.

27 O'Maille ER, Richards TG, Short AH. The influence of conjugation of cholic acid on its uptake and secretion: hepatic extraction of taurocholate and cholate in the dog. $J$ Physiol 1967; 189: 337-50.

28 Scarpello JHB, Sladen GE. Appraisal of the ${ }^{14} \mathrm{C}$ glycocholate test with special reference to the measurement of faecal ${ }^{14}$ C-excretion. Gut 1977; 18: 742-8. 